\title{
Structural brain abnormalities in children and young adults with severe chronic kidney disease
}

\author{
Sophie Lijdsman ${ }^{1}$ (1) Marsh Königs ${ }^{2}$ - Marit S. van Sandwijk ${ }^{3,4}$. Antonia H. Bouts ${ }^{5}$ Koen van Hoeck ${ }^{6}$. \\ Huib de Jong ${ }^{7} \cdot$ Marc Engelen $^{8} \cdot$ Jaap Oosterlaan ${ }^{2} \cdot$ Frederike J. Bemelman $^{3} \cdot$ Kim J. Oostrom $^{1} \cdot$ Jaap W. Groothoff ${ }^{5}$
}

Received: 22 February 2021 / Revised: 13 August 2021 / Accepted: 31 August 2021 / Published online: 20 November 2021

(c) The Author(s) 2021

\begin{abstract}
Background The pathophysiology of neurological dysfunction in severe chronic kidney disease (CKD) in children and young adults is largely unknown. We aimed to investigate brain volumes and white matter integrity in this population and explore brain structure under different treatment modalities.

Methods This cross-sectional study includes 24 patients with severe CKD $($ GFR $<30)$ aged $8-30$ years $($ median $=18.5$, range $=9.1-30.5$ ) on different therapy modalities (pre-dialysis, $n=7$; dialysis, $n=7$; transplanted, $n=10$ ) and 21 healthy controls matched for age, sex, and parental educational level. Neuroimaging targeted brain volume using volumetric analysis on $\mathrm{T} 1$ scans and white matter integrity with tract-based spatial statistics and voxel-wise regression on diffusion tensor imaging (DTI) data.

Results CKD patients had lower white matter integrity in a widespread cluster of primarily distal white matter tracts compared to healthy controls. Furthermore, CKD patients had smaller volume of the nucleus accumbens relative to healthy controls, while no evidence was found for abnormal volumes of gray and white matter or other subcortical structures. Longer time since successful transplantation was related to lower white matter integrity. Exploratory analyses comparing treatment subgroups suggest lower white matter integrity and smaller volume of the nucleus accumbens in dialysis and transplanted patients relative to healthy controls.

Conclusions Young CKD patients seem at risk for widespread disruption of white matter integrity and to some extent smaller subcortical volume (i.e., nucleus accumbens). Especially patients on dialysis therapy and patients who received a kidney transplant may be at risk for disruption of white matter integrity and smaller volume of the nucleus accumbens.
\end{abstract}

Keywords Chronic kidney disease $\cdot$ Magnetic resonance imaging $\cdot$ Adolescents $\cdot$ Kidney failure $\cdot$ Brain structure $\cdot$ Kidney replacement therapy

Sophie Lijdsman

s.lijdsman@amsterdamumc.nl

1 Department of Child and Adolescent Psychiatry \& Psychosocial Care, Amsterdam Reproduction \& Development, Emma Children's Hospital, Amsterdam University Medical Centers (Amsterdam UMC), University of Amsterdam, G8-136, PO Box 22660, 1100 DD Amsterdam, Netherlands

2 Emma Neuroscience Group, Department of Pediatrics, Amsterdam Reproduction \& Development, Emma Children's Hospital, Amsterdam UMC, University of Amsterdam, Amsterdam, Netherlands

3 Department of Nephrology, Amsterdam Infection \& Immunity, Amsterdam UMC, University of Amsterdam, Amsterdam, Netherlands
4 Dianet Dialysis Centre, Amsterdam, Netherlands

5 Department of Pediatric Nephrology, Amsterdam Reproduction \& Development, Emma Children's Hospital, Amsterdam UMC, University of Amsterdam, Amsterdam, Netherlands

6 Department of Pediatrics, University Hospital Antwerp, Edegem, Belgium

7 Department of Pediatrics, Sophia Children's Hospital, Erasmus MC, Rotterdam, Netherlands

8 Department of Pediatric Neurology, Amsterdam Reproduction \& Development, Emma Children's Hospital, Amsterdam UMC, University of Amsterdam, Amsterdam, Netherlands 


\section{Introduction}

Severe chronic kidney disease (CKD) in children and young adults impairs neurocognitive and psychosocial development, characterized by behavioral, social, learning, and vocational problems [1-8]. CKD-induced structural brain abnormalities have been suggested to underlie these disabling difficulties in daily life [5,9]. To date, it is not entirely clear which factors affect the developing brain in patients with CKD. High levels of uremic neurotoxins, osmotic shifts induced by hemodialysis, and cerebral perfusion impairment imposed by hemodialysis and/or immunosuppressive medication in transplanted patients are all considered among the potential pathophysiological mechanisms [9-14].

Studies on the pathophysiology of neurological dysfunction in adults with severe CKD reported smaller brain volumes on magnetic resonance imaging (MRI) scans, indicative of brain atrophy [15-22]. Diffusion tensor imaging (DTI) is an advanced MRI method that is particularly sensitive to the microstructure of white matter tracts [23]. Studies using DTI showed disrupted white matter integrity in adult patients with severe CKD [16, 20, 21, 24-26]. Comparisons of treatment subgroups in adults further indicate that dialysis patients are particularly at risk of brain atrophy and reduced white matter integrity, while the anomalies in transplanted patients are less pronounced $[15-22,27,28]$. Pre-dialysis patients appear to be at the lowest risk of brain abnormalities [28]. Longitudinal studies in transplanted adult patients yield inconsistent findings, with some studies showing improvement and others showing further deterioration of MRI parameters after transplantation $[9,27,29,30]$. Higher uremic toxin levels and longer dialysis duration were related to more severe brain atrophy and disruption of white matter integrity in adults $[18,21,22,24,26,31]$. Taken together, previous studies indicate that CKD and kidney replacement therapy are related to structural abnormalities in the adult brain. As rapid brain development takes place well into early adulthood [32], children and young adults may be particularly sensitive to the detrimental effects of CKD on the developing brain. Indeed, the limited available studies in young CKD patients indicate that CKD may affect normal brain development $[9,33-35]$. The exact mechanisms of CKD that impact on the developing brain remain unclear however, and studies comparing patients on conservative therapy, dialysis, or living with a functional kidney graft are lacking in particular.

The current MRI study aims to explore the impact of (1) CKD on brain structure (as quantified by brain volumetry and tract-based spatial statistics on DTI as a measure of white matter microstructural integrity) and (2) different treatment modalities on brain structure. Based on the available literature in adults, it was expected that children and young adults with severe CKD had smaller brain volumes and lower white matter integrity compared to matched controls, where patients on dialysis therapy would be particularly at risk.

\section{Methods}

\section{Participants}

We included 24 patients with severe CKD aged 8.0-30.9 years and 21 healthy controls matched for age, sex, and parental educational level. CKD patients were recruited from the Amsterdam University Medical Centers $(n=21)$; Erasmus Medical Centre, Netherlands $(n=1)$; and the University Hospital Antwerp, Belgium $(n=2)$. Inclusion criteria for the CKD group were (1) CKD stages 4-5 on conservative therapy, on peritoneal or hemodialysis or patients having received a kidney transplant at least two years prior to enrollment (to ensure stable kidney function), and (2) aged between 8 years (in line with national ethical guidelines) and 30 years. Healthy controls were recruited through participating patients (friends or acquaintances, not siblings) or through local schools and sport clubs. For both patients and controls, exclusion criteria were (1) previously established severe intellectual impairment with overt learning disability; (2) insufficient mastery of the Dutch language; (3) primary sensory disorder (hearing or vision impairments); (4) established skull or brain abnormalities not related to CKD; or (5) co-existing disease with primary or secondary central nervous system involvement interfering with the impact of CKD.

\section{Treatment subgroups}

Three treatment subgroups of CKD patients were distinguished: (1) a pre-dialysis group $(n=7)$ with current estimated glomerular filtration rate $(\mathrm{eGFR})<30 \mathrm{ml} / \mathrm{min} / 1.73$ $\mathrm{m}^{2}$ on conservative treatment at time of assessment; (2) a group on chronic hemodialysis or peritoneal dialysis (total $n=7$, hemodialysis $n=2$, peritoneal dialysis $n=5)$; and (3) a transplanted group $(n=10)$ of patients with a functioning kidney graft for at least 2 years and eGFR $>30 \mathrm{ml} / \mathrm{min} / 1.73 \mathrm{~m}^{2}$ [36]. CKD patients who previously underwent kidney transplantation, but had an eGFR $<30$ at time of assessment, were allocated to either the pre-dialysis or dialysis group according to their current treatment mode. 


\section{Measurements}

\section{Socio-demographic and CKD clinical parameters}

Socio-demographic parameters (i.e., age, sex, parental educational level) were collected via an online portal [37], using a self-developed widely used custom-made inventory. Parental educational level was divided into three categories: (1) low education (primary education, lower vocational education, lower and middle general secondary education); (2) middle education (middle vocational education, higher secondary education, pre-university education); and (3) high education (higher vocational education, university) [38]. The following clinical parameters were extracted from each patient's medical file: age at severe CKD diagnosis (when eGFR first dropped below $30 \mathrm{ml} / \mathrm{min} / 1.73 \mathrm{~m}^{2}$ ), primary disease, history of relevant comorbidities (extreme prematurity $[<32$ weeks of gestational age], malignant hypertension [extremely high blood pressure resulting in organ damage], and convulsions), current eGFR, creatinine and urea blood levels obtained closest to the date of study participation (range of lab measurements: -51 days to +4 days relative to MRI scan), duration of severe CKD (ratio of the time frame between the moment that eGFR dropped below $30 \mathrm{ml} / \mathrm{min} / 1.73 \mathrm{~m}^{2}$ and the time of assessment [months] to calendar age [months], expressed as \% of life), type of dialysis received during lifetime (hemodialysis, peritoneal dialysis, or both), dialysis duration (ratio of dialysis duration [months] to calendar age [months], i.e., $\%$ of life), type of transplantation (pre-emptive or non-preemptive) and time since successful transplantation (ratio of period since transplantation during which eGFR $>30 \mathrm{ml} /$ $\min / 1.73 \mathrm{~m}^{2}$ [months] to calendar age [months], i.e., \% of life). eGFR was calculated using Schwarz formula for patients aged $<18$ years [39] and the abbreviated Modification of Diet in Renal Disease formula was used for patients aged $>18$ [40]. Due to large fluctuations in eGFR prior to and after dialysis, eGFR of patients receiving dialysis was conservatively set at 10 [41].

\section{MRI acquisition and pre-processing}

MRI scans were acquired on a 3.0 T Philips Achieva scanner using a 32-channel head coil. T1-weighted and spin echo diffusion-weighted images using 128 diffusion gradient directions were acquired. Pre-processing of T1 data produced normalized brain volumes of gray matter, white matter, and bilateral subcortical structures (i.e., thalamus, caudate nucleus, putamen, pallidum, hippocampus, amygdala, and nucleus accumbens). Pre-processing of diffusionweighted images produced maps for fractional anisotropy (FA) and mean diffusivity (MD) as the primary measures of white matter integrity (higher FA and lower MD values are consistent with higher integrity [23]). Secondary measures were axial diffusivity (AD) and radial diffusivity (RD), for which a pattern of lower AD and higher RD is consistent with axonal degeneration and/or demyelination [23]. Further details on the MRI acquisition and preprocessing are provided in Supplement 1.

\section{Procedure}

The study protocol was approved by the Medical Ethics Committee of the Amsterdam UMC (NL61708.018.17), and all procedures were performed according to the Declaration of Helsinki. Eligible patients were first approached by their treating physician. Eligible controls were approached by the researcher and received a flyer. Those who responded positively were again contacted, either in person or by phone, for additional information and received a comprehensive information letter. After 2 weeks, potential candidates were re-contacted by telephone to answer remaining questions. After obtaining verbal consent to participate, written informed consent was obtained from legal guardians (for children aged $<16$ years old) and/or children and young adults aged $\geq 12$ years.

One week prior to the MRI scan, participants and/or parents of participants $<18$ years old completed the online questionnaires. The 30-min MRI scan took place at the Amsterdam Medical Centre. If children expressed that they wanted to become familiar with scanning procedures, a simulation scanner was available and a mock procedure was performed before actual scanning.

\section{Statistical analyses}

\section{Socio-demographic and clinical characteristics}

Statistical analyses were performed using SPSS 26.0 (IBM Corp., 2019). Independent and dependent variables were tested for normality and screened for outliers $( \pm 3$ interquartile ranges below/above the lower or upper quartile), which were rescaled using winsorizing (Field, 2009). All groups (CKD group, healthy control group, and treatment subgroups) were compared with each other by age, sex, and parental educational level and clinical parameters using analysis of variance (ANOVA).

\section{Analysis of possible confounders}

Matching between the total CKD and the healthy control group by age, sex, and parental educational level during recruitment controlled for possible confounding effects of socio-demographic factors in these analyses [32, 42]. With regard to treatment subgroup comparisons and analyses of clinical parameters, we explored the association between 
socio-demographic parameters and all outcome measures using correlation analyses (age), $t$ tests (sex), and ANOVAs (parental educational level). Socio-demographic parameters that showed a significant relationship with a particular outcome measure were added as covariates to treatment subgroup comparisons and analyses of clinical parameters on these specific outcomes.

\section{Brain volumes in CKD groups and healthy control group}

Regarding brain volume, group differences (CKD group, healthy control group) were assessed and treatment subgroup differences (pre-dialysis group, dialysis group, transplanted group, healthy control group) were explored using ANOVA. Main effects of treatment subgroup were followed by planned contrasts comparing each treatment subgroup to the healthy control group. Group differences in brain volumes between non-pre-emptively and pre-emptively transplanted patients were explored using $t$ tests. The relationship between clinical parameters (age at severe CKD diagnosis, current eGFR, severe CKD duration, dialysis duration, and time since successful transplantation) was investigated using multivariate linear regressions with backward elimination (criterion for removal: $p>0.10$ ) on brain volumes for which a significant effect of treatment subgroup was found, in order to reduce amount of comparisons.

\section{White matter integrity in CKD groups and healthy control group}

Statistical analyses of DTI maps were performed using randomize [43]. Group differences and treatment subgroup differences were evaluated using voxel-wise comparisons of the skeletonized FA and MD maps. Group differences between the non-pre-emptive and pre-emptive group were also explored. The relation between clinical parameters and white matter integrity was investigated using voxel-wise regression on FA and MD maps. Only in case a significant cluster was identified for FA or MD maps, the origin of the impact of CKD was further investigated by comparing the mean $\mathrm{AD}$ and $\mathrm{RD}$ extracted from the cluster affected by CKD.

Finally, to identify the white matter tracts contributing to the neuropathology of CKD, masks of (bilateral) white matter tracts were created for the following tracts: genu, body and splenium of corpus callosum (CC), corticospinal tract (CST), anterior thalamic radiation (ATR), superior and longitudinal fasciculus (SLF and ILF), inferior frontal occipital fasciculus (IFOF), forceps major and minor (FMa and FMi), cingulate and hippocampal parts of the cingulum bundle (CB), and uncinate fasciculus (UF). Overlap between each white matter tract and the cluster affected by CKD was used to assess (1) which white matter tracts contributed to the impact of CKD (i.e., percentage overlap of each white matter tract with the total cluster affected by CKD) and (2) to what extent each white matter tract was affected by CKD (i.e., percentage overlap of affected cluster with each complete white matter tract).

All statistical testing was two-sided and alpha was set at 0.05 . Cohen's $d$ effect sizes are reported where appropriate and were interpreted as small $(d<0.5)$, medium $(0.5 \geq d<0.8)$, or large $(d \geq 0.80)$ [44].

\section{Results}

\section{Socio-demographic and clinical characteristics}

Socio-demographic and clinical characteristics of the sample are shown in Table 1. Comparisons between the healthy control group, the CKD group, and the treatment subgroups revealed no significant differences on any of the socio-demographic parameters. Regarding clinical parameters, age at severe CKD diagnosis was significantly higher in the dialysis group than in the transplanted group ( $p=0.015, d=1.41)$. As expected, treatment subgroups differed in terms of eGFR and blood urea level, where the transplanted group had higher eGFR and lower blood urea levels than both the pre-dialysis and dialysis group ( $p s<0.001, d s>2.16$ ), while the pre-dialysis group had lower blood urea levels than the dialysis group ( $p=0.029, d=1.20)$. As expected, time since successful transplantation was longer in the transplanted group than in the pre-dialysis and dialysis group $(p<0.001$, $d=2.07$ and $p<0.001, d=2.09$, respectively). Other comparisons on clinical parameters did not reveal significant differences.

\section{Brain volumes in CKD groups and healthy control group}

Table 2 provides the results of the volumetric analysis. As compared to the healthy control group, the CKD group had smaller volume of the nucleus accumbens ( $p=0.005$, $d=-0.87)$. No further significant differences between the CKD group and healthy control group were found for volumes of the gray matter, white matter, or subcortical structures $(p s>0.072)$. Exploratory analyses comparing treatment subgroups showed a significant main effect of treatment type for volume of the nucleus accumbens $(p=0.022)$. No significant main effect of treatment type was found for volumes of gray and white matter or other subcortical structures $(p s>0.222)$. Subsequent analyses revealed that, as compared to the healthy control group, both the dialysis and transplanted groups had smaller nucleus accumbens volume $(p=0.037, d=-0.94$; 
Table 1 Demographic and clinical parameters in the CKD, pre-dialysis, dialysis, transplanted, and healthy control group

\begin{tabular}{|c|c|c|c|c|c|c|c|c|c|}
\hline & \multicolumn{2}{|l|}{ Group } & \multicolumn{2}{|c|}{ Contrasts } & \multicolumn{3}{|c|}{ Treatment subgroups } & \multicolumn{2}{|l|}{ Statistics } \\
\hline & CKD & $\begin{array}{l}\text { Healthy } \\
\text { controls }\end{array}$ & $p$ & $d$ & Pre-dialysis & Dialysis & Transplanted & $p$ & Contrasts \\
\hline$n$ & 24 & 21 & & & 7 & 7 & 10 & & \\
\hline Age & $18.5(9.1-30.5)$ & $\begin{array}{l}19.8 \\
(9.0-29.2)\end{array}$ & 0.933 & 0.03 & $15.5(9.1-26.6)$ & $21.3(9.6-27.1)$ & $17.8(9.1-30.5)$ & 0.310 & \\
\hline Male & $n=16(66.7 \%)$ & $\begin{array}{l}n=13 \\
\quad(61.9 \%)\end{array}$ & 0.746 & -0.10 & $n=6(85.7 \%)$ & $n=3(42.9 \%)$ & $n=7(70.0 \%)$ & 0.249 & \\
\hline $\begin{array}{l}\text { Educational level of } \\
\text { parents }^{\mathrm{a}}\end{array}$ & $2.0(1.0-3.0)$ & $2.0(1.0-3.0)$ & 0.890 & 0.05 & $2.0(2.0-3.0)$ & $2.0(1.0-3.0)$ & $2.0(1.0-3.0)$ & 0.661 & \\
\hline $\begin{array}{l}\text { Age at severe CKD } \\
\text { diagnosis (years) }\end{array}$ & $14.0(0.0-24.7)$ & & & & $13.8(1.9-24.7)$ & $20.2(9.3-24.0)$ & $8.1(0.0-22.8)$ & 0.049 & $\mathrm{D}>\mathrm{Tx}$ \\
\hline \multicolumn{10}{|l|}{ Primary disease $(n)$} \\
\hline$\bullet$ CAKUT $^{1}$ & 7 & & & & 3 & - & 4 & & \\
\hline - Renovascular ${ }^{2}$ & 2 & & & & - & - & 2 & & \\
\hline $\begin{array}{l}\text { - Cortical } \\
\text { necrosis }^{3}\end{array}$ & 3 & & & & - & 2 & 1 & & \\
\hline $\begin{array}{l}\text { - Acquired } \\
\text { glomerulopathy }\end{array}$ & 2 & & & & 1 & 1 & - & & \\
\hline $\begin{array}{l}\text { - Inherited } \\
\text { nephropathy }{ }^{5}\end{array}$ & 7 & & & & 2 & 3 & 2 & & \\
\hline $\begin{array}{l}\text { - Other and } \\
\text { unknown cause }\end{array}$ & 3 & & & & 1 & 1 & 1 & & \\
\hline \multicolumn{10}{|c|}{ History of relevant comorbidities } \\
\hline $\begin{array}{l}\text { - Extreme } \\
\text { prematurity } \\
(<32 \text { weeks of } \\
\text { GA })\end{array}$ & 1 & & & & - & - & 1 & & \\
\hline $\begin{array}{l}\text { - Malignant } \\
\text { hypertension }\end{array}$ & 5 & & & & - & 2 & 3 & & \\
\hline $\begin{array}{l}\text { - Convulsions/his- } \\
\text { tory of epilepsy }\end{array}$ & 2 & & & & - & 1 & 1 & & \\
\hline $\begin{array}{l}\text { eGFR }(\mathrm{ml} / \mathrm{min} / 1.73 \\
\left.\mathrm{m}^{2}\right)\end{array}$ & $26.6(10.0-90.0)$ & & & & $24.8(11.3-29.0)$ & $10.0(10.0-10.0)$ & $52.9(31.0-90.0)$ & $<0.001$ & $\begin{array}{l}\text { Tx }>P D \\
\& D\end{array}$ \\
\hline Urea $(\mathrm{mmol} / \mathrm{L})$ & $14.9(5.1-25.1)$ & & & & $16.8(13.7-20.7)$ & $20.7(16.8-28.8)$ & $7.6(5.1-13.3)$ & $<0.001$ & $\mathrm{D}>\mathrm{PD}>\mathrm{Tx}$ \\
\hline $\begin{array}{l}\text { Duration severe CKD } \\
\text { (\% of life) }\end{array}$ & $12 \%(0-81 \%)$ & & & & $11 \%(0-81 \%)$ & $8 \%(3-21 \%)$ & $20 \%(4-78 \%)$ & 0.347 & \\
\hline $\begin{array}{l}\text { Ever treated by dialy- } \\
\text { sis }(n)\end{array}$ & 14 & & & & 2 & 7 & 5 & & \\
\hline Hemodialysis & 5 & & & & 2 & 2 & 1 & & \\
\hline Peritoneal dialysis & 8 & & & & - & 5 & 3 & & \\
\hline Both & 1 & & & & - & - & 1 & & \\
\hline $\begin{array}{l}\text { Duration dialysis (\% } \\
\text { of life) }\end{array}$ & $1 \%(0-49 \%)$ & & & & $0 \%(0-6 \%)$ & $4 \%(1-14 \%)$ & $2 \%(0-49 \%)$ & 0.371 & \\
\hline $\begin{array}{l}\text { Ever treated by kidney } \\
\text { transplantation }(n)\end{array}$ & 13 & & & & 2 & 1 & 10 & & \\
\hline Pre-emptive & 6 & & & & 1 & - & 5 & & \\
\hline Non-pre-emptive & 7 & & & & 1 & 1 & 5 & & \\
\hline $\begin{array}{l}\text { Time since kidney } \\
\text { transplantation (\% } \\
\text { of life) }\end{array}$ & $6 \%(0-61 \%)$ & & & & $0 \%(0-6 \%)$ & $0 \%(0-10 \%)$ & $23 \%(13-61 \%)$ & $<0.001$ & $\begin{array}{c}\mathrm{Tx}>\mathrm{PD} \\
\& \mathrm{D}\end{array}$ \\
\hline
\end{tabular}

Values are displayed as median (range), unless otherwise indicated. Abbreviations: $\mathrm{CKD}=$ chronic kidney disease; $\mathrm{D}=$ dialysis group; eGFR = estimated glomerular filtration rate; $\mathrm{GA}=$ gestational age; $\mathrm{PD}=$ pre-dialysis group; $\mathrm{Tx}=$ transplanted group. ${ }^{\mathrm{a}} 1.0=$ low education, $2.0=$ middle education, $3.0=$ high education

Primary diseases: ${ }^{1}$ urethral valves $(n=6)$, dysplasia $(n=1),{ }^{2}$ malignant hypertension $(n=2),{ }^{3}$ due to asphyxia $(n=1)$, due to septicemia $(n=2)$; ${ }^{4}$ primary focal segmental glomerulosclerosis (FSGS) $(n=1)$, anti-neutrophil cytoplasmic autoantibodies (ANCA) vasculitis $(n=1) ;{ }^{5}$ branchiootorenal (BOR-) syndrome $(n=1)$, NPHP1 mutation $(n=1)$, autosomal dominant polycystic kidney disease (ADPKD) $(n=1)$, Alport's syndrome $(n=1)$, inherited FSGS due to INF2 mutation $(n=2)$, Pax-2 mutation $(n=1) ;{ }^{6}$ tubulointerstitial nephritis $(n=1)$, unknown cause $(n=2)$ 


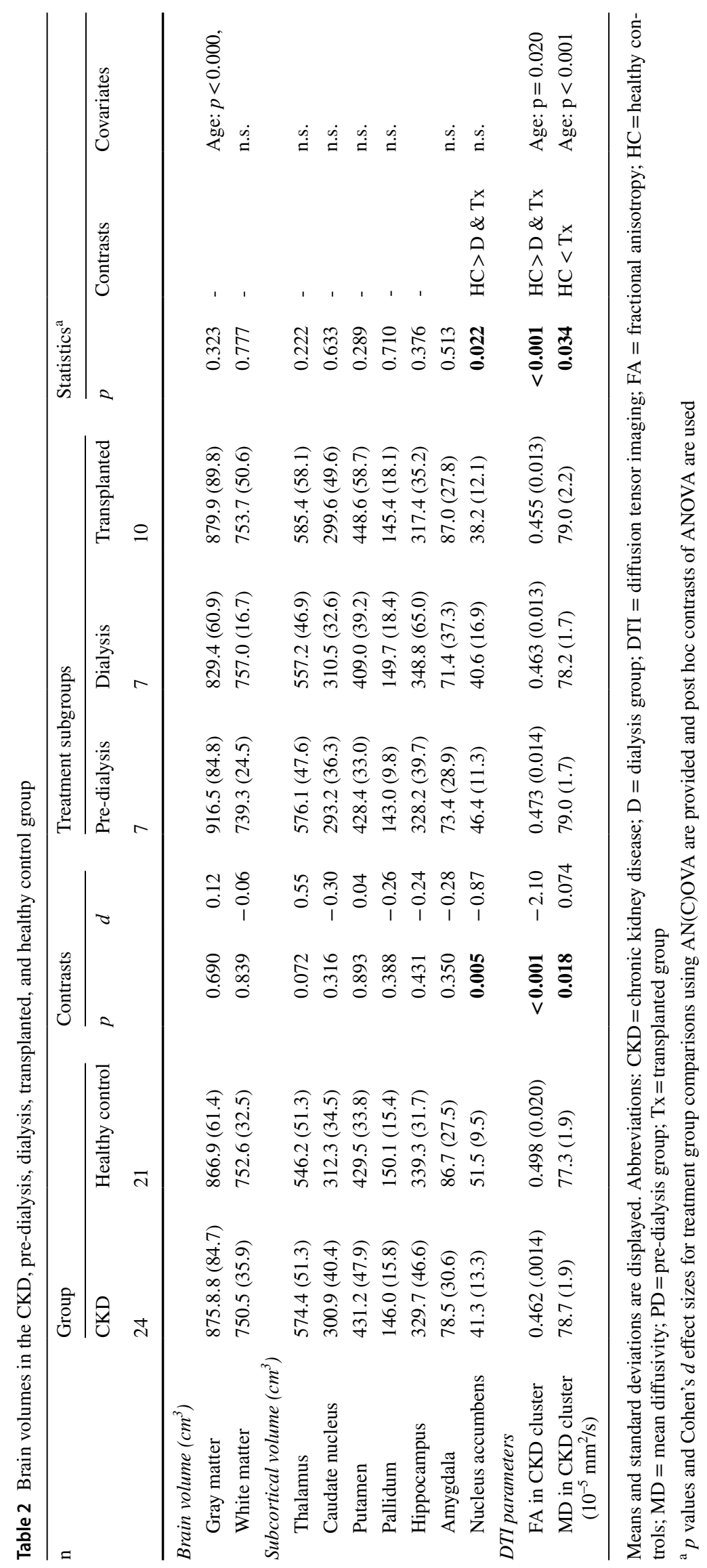


Table 3 Brain volumes and DTI parameters in non-pre-emptive and pre-emptive transplantation groups

\begin{tabular}{|c|c|c|c|c|}
\hline \multirow[t]{3}{*}{$n$} & \multicolumn{2}{|l|}{ Groups } & \multicolumn{2}{|c|}{ Contrasts } \\
\hline & Non-pre-emptive & Pre-emptive & $p$ & $d$ \\
\hline & 7 & 6 & & \\
\hline \multicolumn{5}{|l|}{ Brain volume $\left(\mathrm{cm}^{3}\right)$} \\
\hline Gray matter & $858.9(93.6)$ & $909.4(102.3)$ & 0.373 & -0.52 \\
\hline White matter & $757.3(23.7)$ & $741.1(44.7)$ & 0.538 & -0.46 \\
\hline Thalamus & $603.9(46.9)$ & $563.2(56.6)$ & 0.183 & 0.79 \\
\hline $\begin{array}{l}\text { Caudate } \\
\text { nucleus }\end{array}$ & $300.3(51.3)$ & $300.4(50.9)$ & 0.996 & 0.00 \\
\hline Putamen & $447.6(42.9)$ & $443.5(68.0)$ & 0.897 & 0.07 \\
\hline Pallidum & $148.5(13.6)$ & $143.3(19.8)$ & 0.590 & 0.31 \\
\hline Hippocampus & $331.9(52.5)$ & $329.2(31.5)$ & 0.915 & 0.06 \\
\hline Amygdala & $76.1(26.1)$ & $89.1(34.9)$ & 0.456 & -0.43 \\
\hline $\begin{array}{l}\text { Nucleus accum- } \\
\text { bens }\end{array}$ & $37.9(13.0)$ & 44.4 (13.6) & 0.396 & -0.49 \\
\hline \multicolumn{5}{|l|}{ DTI parameters } \\
\hline $\begin{array}{l}\text { FA in CKD } \\
\text { cluster }\end{array}$ & $0.458(0.011)$ & $0.453(0.013)$ & 0.495 & 0.42 \\
\hline $\begin{array}{l}\mathrm{MD} \text { in } \mathrm{CKD} \\
\text { cluster }\left(10^{-5}\right. \\
\left.\mathrm{mm}^{2} / \mathrm{s}\right)\end{array}$ & $78.6(1.7)$ & $79.6(2.2)$ & 0.477 & -0.51 \\
\hline
\end{tabular}

Means and standard deviations are displayed. Abbreviations: $\mathrm{CKD}=$ chronic kidney disease; $\mathrm{DTI}=$ diffusion tensor imaging; $\mathrm{FA}=$ fractional anisotropy; $\mathrm{MD}=$ mean diffusivity

$p=0.005, d=-1.28$, respectively). Group differences between the non-pre-emptively transplanted and pre-emptively transplanted group were not significant $(p s>0.183$, $d \mathrm{~s}<0.79$; Table 3).

Multiple regression analysis in the total CKD group did not reveal a significant association between clinical parameters and the subcortical structure with an observed effect of treatment subgroup (i.e., nucleus accumbens).

\section{White matter integrity in CKD groups and healthy control group}

Voxel-wise group comparisons revealed that the CKD group had lower FA and higher MD than the healthy control group in a large cluster of white matter tracts $(p<0.001, d=-2.10$; $p=0.018, d=0.74$, respectively), as displayed in Fig. 1a. Subsequent analyses showed that within this affected cluster, the CKD group had higher $\mathrm{RD}(p<0.001, d=1.52)$ and lower $\mathrm{AD}(p=0.002, d=-1.01)$ as compared to the healthy control group. When considering individual white matter tracts, the IFOF, ATR, and SLF had the highest contribution to the cluster affected by CKD and the CC, CB, FMa, and FMi had least or no contribution. The IFOF, UF, ATR, and CST were most extensively affected by CKD and the CC and CB were not or barely affected (Table 4).
Exploratory voxel-wise group comparisons of the treatment subgroups on FA and MD maps showed no difference between the pre-dialysis group and healthy control group, while the dialysis group had lower FA in a large cluster of white matter tracts compared to the healthy control group ( $p<0.001, d=-1.92)$ (Fig. 1b). The transplanted group had both lower FA and higher MD in a large cluster of white matter tracts $(p<0.001, d=-2.40 ; p=0.034, d=0.81$, respectively). Follow-up analyses on AD and RD maps showed that within the cluster of affected white matter, both the dialysis and transplanted group had higher $\operatorname{RD}(p=0.005, d=1.30$; $p<0.001 d=1.68$, respectively) and lower $\operatorname{AD}(p=0.003$, $d=-1.52 ; p=0.002, d=-1.27$, respectively) compared to the healthy control group. No significant differences were found between the non-pre-emptive and pre-emptive transplantation group. Voxel-wise regression analysis revealed that longer time since successful transplantation was significantly related to lower FA $(\beta=-0.518, p=0.011$, while no relations were found with $\mathrm{MD}, \mathrm{RD}$, and $\mathrm{AD}$ (Fig. 2). No other significant relations between clinical parameters and white matter integrity were revealed.

\section{Discussion}

The results of this exploratory MRI study suggest that CKD patients aged 8 to 30 years are at risk for widespread abnormality of DTI parameters in the cerebral white matter. These findings are consistent with the hypothesis that CKD results in disruption of white matter integrity indicative of axonal damage and/or demyelination. White matter abnormalities may contribute to the presence of neurocognitive impairments that are considered prominent in the clinical features of CKD [2-7]. No evidence was found for smaller brain volume of the gray and white matter, although there were indications for smaller volume of a subcortical structure (i.e., nucleus accumbens). Our findings further suggest that longer time since successful transplantation may be related to more severe disruption of white matter integrity. Additional exploratory comparisons between treatment subgroups further suggest that dialysis and transplanted patients may both be vulnerable for disruption of white matter integrity and to some extent smaller subcortical volumes (i.e., in the nucleus accumbens), with no evident differences between the two groups. In contrast, no evidence was found for structural brain abnormalities in pre-dialysis patients with severe CKD.

Findings from DTI analyses suggest that our patients have widespread disruption of white matter integrity. The observed effect of severe CKD on white matter integrity is in line with previous studies showing a negative impact of CKD on the adult brain [16, 20-22, 24-26] and the only existing DTI study in young CKD patients that found 
Fig. 1 Illustration of voxel-wise TBSS comparisons of FA and MD maps, using threshold-free cluster enhancement correction, showing significantly lower white matter integrity in CKD patients (A) and dialysis and transplanted patients (B) compared to healthy controls. For treatment subgroup comparisons, age was included as covariate to control for confounding effects, as age varied among treatment subgroups and had a significant effect on FA and MD maps. Red-yellow clusters show reduced FA values in the CKD groups compared to the healthy controls. Blue-lightblue clusters show increased MD values in the CKD groups. More yellow and lighter blue areas indicate higher significant values. All images are illustrated at the same coordinates $(x=-15, y=-16, z=13)$ and show the whole brain skeleton (at FA $>0.3$, in green), overlaid on standard MNI $1521 \mathrm{~mm}$ T1 brain. Significant group differences are "thickened" towards the full width of the white matter tract to increase visualization. Abbreviations: $\mathrm{CKD}=$ chronic kidney disease; $\mathrm{FA}=$ fractional anisotropy; $\mathrm{MD}=$ mean diffusivity; $\mathrm{L}=$ left

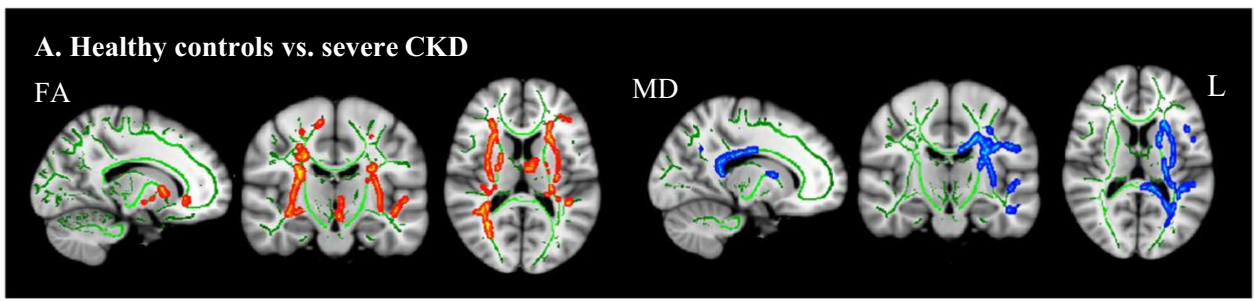

B. CKD treatment groups

Healthy controls vs. Predialysis patients

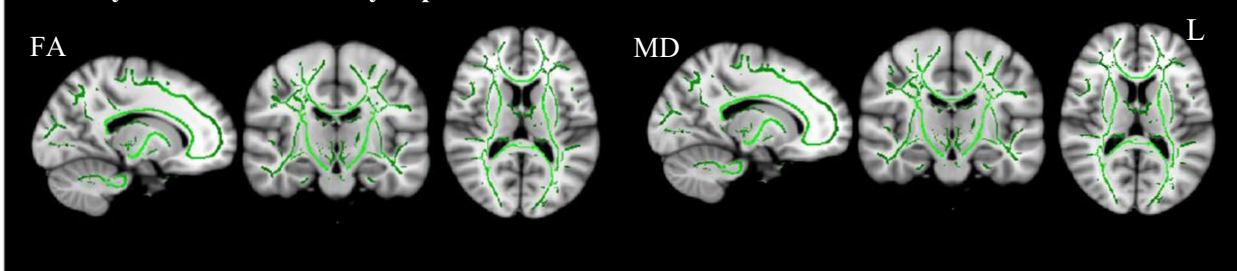

Healthy controls vs. Dialysis patients

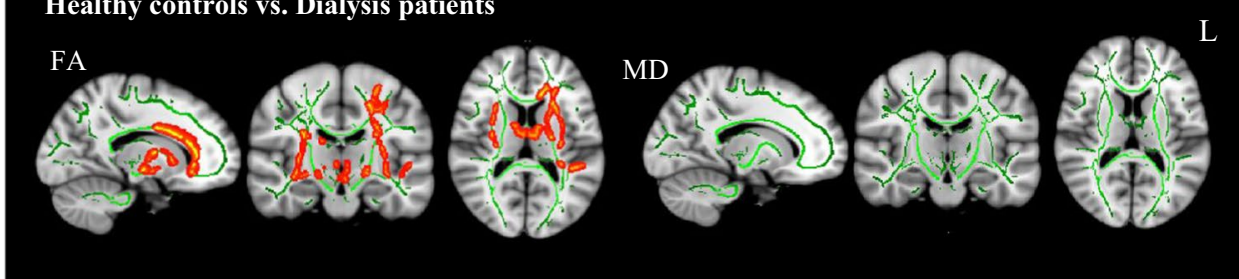

Healthy controls vs. Transplanted patients

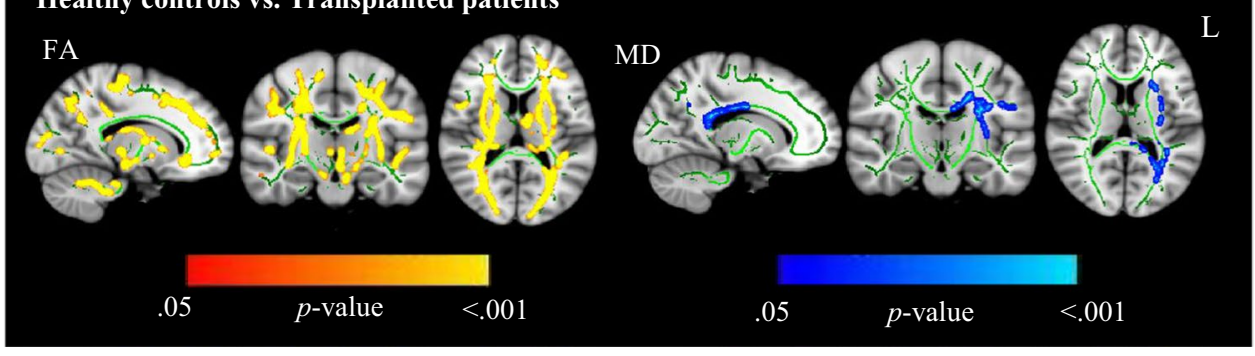

relatively modest abnormality of white matter integrity [33]. Our study extends the existing literature by showing that the negative impact of CKD on white matter tracts in young patients is widespread, where the larger distal white matter tracts (i.e., IFOF, ATR, SLF, CST, and UF) seem more prominently involved than medial white matter tracts (i.e., CC, CB, FMA, and FMi). Additionally, findings from volumetric analysis further indicate that young patients with severe CKD may have smaller volume of the nucleus accumbens, while no evidence was found for smaller brain volume of gray and white matter or other subcortical structures. These findings contribute to already inconsistent literature on the impact of CKD on brain volumes of young patients $[34,35]$. The nucleus accumbens is a subcortical structure involved in behavioral arousal and the regulation of slowwave sleep [45]. This may suggest that abnormal development of this structure plays a role in the clinical presentation of CKD in young patients, as sleep is often disturbed in these patients [46]. The observed effect on the nucleus accumbens contrasts with the single previous study on subcortical volumes in young patients, reporting no effects of CKD on subcortical volumes [34]. This discrepancy may be explained by higher CKD severity in our study sample (eGFR $<30$, while also including dialysis patients). However, our results are in line with a study in older dialysis patients, which also reported smaller volume of the nucleus accumbens [16]. Taken together, these findings may support the idea that subcortical structures may be more vulnerable in patients with more severe stages of CKD. To conclude, our combined results of DTI and volumetric analyses indicate that abnormal white matter integrity is prominently implicated in the effect of CKD on the young brain. In addition, there is some evidence indicating a negative effect on subcortical structures, more specifically the nucleus accumbens.

Exploratory analyses comparing treatment subgroups indicate that dialysis patients have structural brain 
Table 4 White matter tracts involved in the impact of severe CKD

\begin{tabular}{lll}
\hline White matter tract & $\begin{array}{l}\text { Percent- } \\
\text { age of } \\
\text { cluster }\end{array}$ & $\begin{array}{l}\text { Percentage of } \\
\text { tract affected }\end{array}$ \\
\hline $\begin{array}{l}\text { Inferior frontal occipital fasciculus } \\
\quad \text { (IFOF) }\end{array}$ & 23.8 & 26.7 \\
Anterior thalamic radiation (ATR) & 12.6 & 19.1 \\
Superior longitudinal fasciculus (SLF) & 11.5 & 13.8 \\
Cortical spinal tract (CST) & 9.2 & 18.6 \\
Uncinate fasciculus (UF) & 6.4 & 24.5 \\
Inferior longitudinal fasciculus (ILF) & 4.4 & 9.2 \\
Forceps minor (FMi) & 1.3 & 3.1 \\
Forceps major (FMa) & 1.2 & 4.2 \\
Splenium of corpus callosum & 0.1 & 0.6 \\
Body of corpus callosum & 0.1 & 0.4 \\
Hippocampal part of cingulum bundle & 0.0 & 0.0 \\
$\quad$ (HCB) & & \\
Cingulate part of cingulum bundle & 0.0 & 0.0 \\
$\quad$ (CCB) & & \\
Genu of corpus callosum & 0.0 & 0.0 \\
\hline
\end{tabular}

abnormalities (i.e., disruption of white matter integrity and smaller volume of the nucleus accumbens) relative to unaffected peers, while no evidence was found for brain abnormalities in pre-dialysis patients. This is in line with previous studies in children and young adults with CKD on conservative therapy $[33,34]$ and adults on dialysis therapy $[3,9,16$, 25-27, 31]. No associations were found between dialysis duration and severity of the observed brain abnormalities. Although other studies in adults have reported associations between dialysis duration and the volume of gray and white matter [18, 27, 28, 31], the results from this study suggest that the potential impact of dialysis on brain structure may not linearly increase over time in young patients with CKD. In line with absence of evidence for brain abnormalities in our patients on pre-dialysis therapy, no significant associations were found between eGFR and brain structure. This may indicate that eGFR poorly reflects the concentrations of the wide range of protein-bound uremic toxins that may have a negative impact on the brain [47]. This is the first study to investigate brain structure in young patients on dialysis, presenting evidence suggesting the presence of abnormal white matter integrity and smaller subcortical volume (i.e., nucleus accumbens).

Although positive effects of transplantation on white matter integrity could be anticipated from adult studies [27, $29,30]$, findings from our regression analyses suggest that longer time post-transplantation during the patients' lifetime may be related to more pronounced abnormalities in white matter integrity. To our knowledge, this is the first study to expose this relationship in young CKD patients. Our explorative comparisons of treatment subgroups fit with this finding and suggest that transplanted patients may have widespread disruption of white matter integrity and smaller volume of the nucleus accumbens relative to unaffected peers. These findings align with two recent studies in children and young adults $[33,34]$. We found no evidence for striking differences between the pre-emptively transplanted and non-pre-emptively transplanted patients, although this analysis was limited by very small sample sizes. Considering our observations suggesting a role for dialysis therapy in the presence of brain abnormalities, a history of exposure to dialysis may also play a role in the brain abnormalities observed in the transplanted group. However, our findings do suggest that effects of severe CKD on brain structure may not be reversible after transplantation in young patients and may even worsen over time.

The findings of our study suggest that CKD and kidney replacement therapy may impact on axonal integrity. This could imply that white matter abnormalities may become more pronounced over time due to derailed development of white matter tracts after the initial impact of CKD and/ or kidney replacement therapy. Moreover, post-transplant infections and neurotoxic/microvascular damage by immune-suppressive maintenance therapy may also contribute to detrimental effects on brain structure after transplantation $[11,13,48]$. The notion that transplanted patients with a normal eGFR, including pre-emptively transplanted patients, and dialysis patients both appeared to have brain abnormalities gives rise to the thought that ischemia induced by impaired cerebral perfusion may play a more important role in the impact of severe CKD on brain structure than uremic toxins. Hypertension, small vessel disease, and impaired cerebral perfusion indeed commonly occur in CKD [5, 14, 49]. This hypothesis fits with the specific structural brain abnormalities revealed in our study, as widespread disruption of white matter integrity has previously been described in adult patients with hypertension, which is in turn associated with impaired cerebral perfusion [50]. This speculation is in line with a recent review, concluding that CKD-related hypertension may be more important as a risk factor for the influence of pediatric CKD on the brain than initially thought [5].

Future studies using a prospective longitudinal design could further clarify the factors that impact on the developing brain, such as duration of CKD, the impact of kidney replacement therapy, course of uncontrolled hypertension, and neurotoxic and vasoactive immuno-suppressive therapy. Obduction or neurophysiological studies may provide further insights in the neuropathology underlying the observed brain abnormalities in patients with CKD. Future research in larger cohorts could take into account the potential roles of co-morbidities and clinical complications of CKD (e.g., premature birth, epilepsy, prolonged 


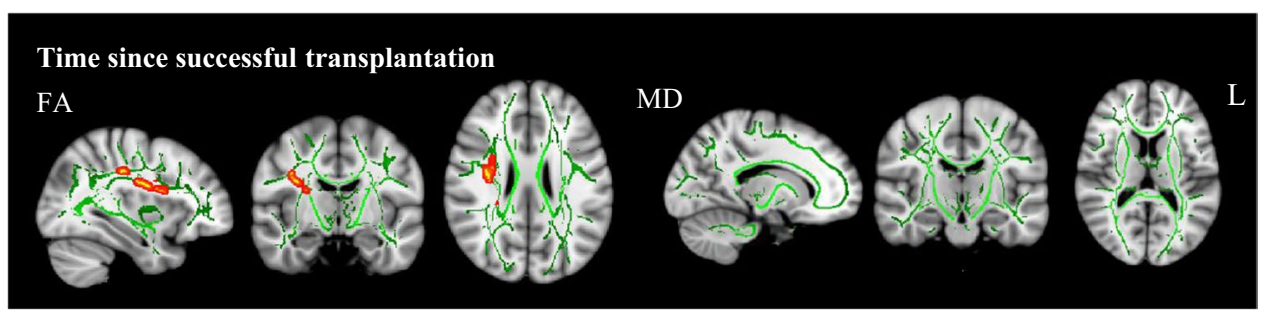

Fig. 2 Illustration of voxel-wise TBSS comparisons of FA and MD maps, using threshold-free cluster enhancement correction, showing a significant negative correlation between time since succesful transplantation and FA values in CKD patients. Image is illustrated the following coordinates: $(x=34, y=-10, z=26)$ and shows the whole

severe acidosis). Likewise, longitudinal studies may contribute to better delineation between direct effects of CKD on the brain and secondary effects that may manifest due to derailed brain development. Furthermore, the relevance of structural brain abnormalities for brain function remains to be investigated, for example, in relation to neurocognitive and adaptive functioning in young CKD patients.

\section{Strengths and limitations}

First, we acknowledge our small sample size. Severe CKD is a rare disease in young patients and much effort was done to establish a collaboration with (inter)national child nephrology centers in order to reach as many Dutchspeaking patients as possible. Very cautious interpretation of our findings is necessary, especially with regard to the additional exploratory treatment subgroup analyses. We encourage further investigation of the neuropathology in dialysis and transplanted patients using prospective, long-term longitudinal designs with multiple repeated measurements to increase rigor of the observations and to follow the course of CKD throughout disease and treatment stages. A second limitation is the heterogeneity of our sample in terms of socio-demographic and illness characteristics, which is also partly due to low prevalence of severe CKD in children and young adults. Careful matching of the healthy control group by age, sex, and parental educational level partly accounted for potential group differences and confounding analyses showed that socio-demographic factors did not account for reported group differences. This study also has several strengths, involving the focus on young patients with CKD, the use of a single MRI scanner in an international patient cohort (as multiple scanning sites introduce noise), and the use of advanced quantitative analyses for a comprehensive investigation of brain structure. brain skeleton (at FA $>0.3$. in green), overlaid on standard MNI 152 $1 \mathrm{~mm}$ T1 brain. Significant group differences are "thickened" towards the full width of the white matter tract to increase visualization. Abbreviations: $\mathrm{FA}=$ fractional anisotropy; $\mathrm{MD}=$ mean diffusivity; $\mathrm{L}=$ left

\section{Conclusion and future directions}

This study suggests that young patients with severe CKD are at risk of structural brain abnormalities, as detected on MRI by showing widespread abnormality of DTI parameters in the white matter. We further found some evidence suggesting smaller volume of subcortical structures (i.e., nucleus accumbens). Especially patients on dialysis therapy and patients who receive a kidney transplant may be at risk for widespread disruption of white matter integrity and smaller volume of the nucleus accumbens. This study suggests that brain abnormalities in young patients with severe CKD may be partly irreversible, possibly even after successful transplantation. Prospective longitudinal studies should determine the effects of kidney transplantation on the developing brain, which may be less favorable than seen in adult patients.

Abbreviations AD: Axial diffusivity; ANOVA: Analysis of variance; ATR: Anterior thalamic radiation; CB: Cingulum bundle; CC: Corpus callosum; CKD: Chronic kidney disease; CST: Corticospinal tract; DTI: Diffusion tensor imaging; eGFR: Estimated glomerular filtration rate; FA: Fractional anisotropy; FMa: Forceps major; FMi: Forceps minor; MD: Mean diffusivity; MRI: Magnetic resonance imaging; RD: Radial diffusivity; UF: Uncinate fasciculus

Supplementary Information The online version contains supplementary material available at https://doi.org/10.1007/s00467-021-05276-5.

Author contribution SL, MK, MSS, FJB, KJO, and JWG participated in research design. SL conducted the research and performed data analyses. SL, MK, JO, KJO, and JWG were involved in the data analyses plan. All authors participated in interpretation of outcomes and participated in the writing of the paper.

Funding This study was partly funded by the Dutch Kidney Foundation.

\section{Declarations}

Conflict of interest The authors declare no competing interests. 
Open Access This article is licensed under a Creative Commons Attribution 4.0 International License, which permits use, sharing, adaptation, distribution and reproduction in any medium or format, as long as you give appropriate credit to the original author(s) and the source, provide a link to the Creative Commons licence, and indicate if changes were made. The images or other third party material in this article are included in the article's Creative Commons licence, unless indicated otherwise in a credit line to the material. If material is not included in the article's Creative Commons licence and your intended use is not permitted by statutory regulation or exceeds the permitted use, you will need to obtain permission directly from the copyright holder. To view a copy of this licence, visit http://creativecommons.org/licenses/by/4.0/.

\section{References}

1. Tjaden LA, Maurice-Stam H, Grootenhuis MA, Jager KJ, Groothoff JW (2016) Impact of renal replacement therapy in childhood on long-term socioprofessional outcomes: a 30-year Follow-Up Study. J Pediatr 171:189-195.e181-182. https://doi. org/10.1016/j.jpeds.2015.12.017

2. Groothoff JW, Grootenhuis M, Dommerholt A, Gruppen MP, Offringa M, Heymans HS (2002) Impaired cognition and schooling in adults with end stage renal disease since childhood. Arch Dis Child 87:380-385

3. Gipson DS, Duquette PJ, Icard PF, Hooper SR (2007) The central nervous system in childhood chronic kidney disease. Pediatr Nephrol 22:1703-1710. https://doi.org/10.1007/s00467-006-0269-1

4. Schoenmaker NJ, Haverman L, Tromp WF, van der Lee JH, Offringa M, Adams B, Bouts AH, Collard L, Cransberg K, van Dyck M, Godefroid N, van Hoeck K, Koster-Kamphuis L, Lilien MR, Raes A, Taylan C, Grootenhuis MA, Groothoff JW (2014) Children of non-Western origin with end-stage renal disease in the Netherlands, Belgium and a part of Germany have impaired health-related quality of life compared with Western children. Nephrol Dial Transplant 29:448-457. https://doi.org/10.1093/ ndt/gft436

5. Harshman LA, Hooper SR (2020) The brain in pediatric chronic kidney disease-the intersection of cognition, neuroimaging, and clinical biomarkers. Pediatr Nephrol. https://doi.org/10.1007/ s00467-019-04417-1

6. Ruebner RL, Laney N, Kim JY, Hartung EA, Hooper SR, Radcliffe J, Furth SL (2016) Neurocognitive dysfunction in children, adolescents, and young adults with CKD. Am J Kidney Dis 67:567-575. https://doi.org/10.1053/j.ajkd.2015.08.025

7. Slickers J, Duquette P, Hooper S, Gipson D (2007) Clinical predictors of neurocognitive deficits in children with chronic kidney disease. Pediatr Nephrol 22:565-572. https://doi.org/10. 1007/s00467-006-0374-1

8. Splinter A, Tjaden LA, Haverman L, Adams B, Collard L, Cransberg K, van Dyck M, Van Hoeck KJ, Hoppe B, KosterKamphuis L, Lilien MR, Raes A, Taylan C, Grootenhuis MA, Groothoff JW (2018) Children on dialysis as well as renal transplanted children report severely impaired health-related quality of life. Qual Life Res 27:1445-1454. https://doi.org/10.1007/ s11136-018-1789-4

9. Moodalbail DG, Reiser KA, Detre JA, Schultz RT, Herrington JD, Davatzikos C, Doshi JJ, Erus G, Liu HS, Radcliffe J, Furth SL, Hooper SR (2013) Systematic review of structural and functional neuroimaging findings in children and adults with CKD. Clin J Am Soc Nephrol 8:1429-1448. https://doi.org/10.2215/ CJN.11601112
10. Ohtsuki S, Asaba H, Takanaga H, Deguchi T, Hosoya K, Otagiri M, Terasaki T (2002) Role of blood-brain barrier organic anion transporter 3 (OAT3) in the efflux of indoxyl sulfate, a uremic toxin: its involvement in neurotransmitter metabolite clearance from the brain. J Neurochem 83:57-66. https://doi.org/10.1046/j. 1471-4159.2002.01108.x

11. Parvex P, Pinsk M, Bell LE, O'Gorman AM, Patenaude YG, Gupta IR (2001) Reversible encephalopathy associated with tacrolimus in pediatric renal transplants. Pediatr Nephrol 16:537542. https://doi.org/10.1007/s004670100602

12. Tantisattamo E, Molnar MZ, Ho BT, Reddy UG, Dafoe DC, Ichii H, Ferrey AJ, Hanna RM, Kalantar-Zadeh K, Amin A (2020) Approach and Management of hypertension after kidney transplantation. Front Med (Lausanne) 7:229. https://doi.org/10.3389/ fmed.2020.00229

13. Van Sandwijk MS, Ten Berge IJ, Majoie CB, Caan MW, De Sonneville LM, Van Gool WA, Bemelman FJ (2016) Cognitive changes in chronic kidney disease and after transplantation. Transplantation 100:734-742. https://doi.org/10.1097/TP.0000000000 000968

14. Wolfgram DF (2019) Intradialytic cerebral hypoperfusion as mechanism for cognitive impairment in patients on hemodialysis. J Am Soc Nephrol 30:2052-2058. https://doi.org/10.1681/ASN. 2019050461

15. Chang CY, Lin CC, Tsai CF, Yang WC, Wang SJ, Lin FH, Fuh JL (2017) Cognitive impairment and hippocampal atrophy in chronic kidney disease. Acta Neurol Scand 136:477-485. https://doi.org/ 10.1111/ane. 12753

16. Chiu YL, Tsai HH, Lai YJ, Tseng HY, Wu YW, Peng YS, Chiu CM, Chuang YF (2019) Cognitive impairment in patients with end-stage renal disease: accelerated brain aging? J Formos Med Assoc 118:867-875. https://doi.org/10.1016/j.jfma.2019.01.011

17. Meurs M, Roest AM, Groenewold NA, Franssen CF, Westerhuis $\mathrm{R}$, Kloppenburg WD, Doornbos B, Beukema L, Lindmäe H, de Groot JC, van Tol MJ, de Jonge P (2016) Gray matter volume and white matter lesions in chronic kidney disease: exploring the association with depressive symptoms. Gen Hosp Psychiatry 40:18-24. https://doi.org/10.1016/j.genhosppsych.2016.02.005

18. Prohovnik I, Post J, Uribarri J, Lee H, Sandu O, Langhoff E (2007) Cerebrovascular effects of hemodialysis in chronic kidney disease. J Cereb Blood Flow Metab 27:1861-1869. https://doi.org/ 10.1038/sj.jcbfm.9600478

19. Qiu Y, Lv X, Su H, Jiang G, Li C, Tian J (2014) Structural and functional brain alterations in end stage renal disease patients on routine hemodialysis: a voxel-based morphometry and resting state functional connectivity study. PLoS One 9:e98346. https:// doi.org/10.1371/journal.pone.0098346

20. Schaier M, Wolf RC, Kubera K, Nagel S, Bartsch A, Zeier M, Bendszus M, Herweh C (2019) Vasogenic brain edema during maintenance hemodialysis : preliminary results from tract-based spatial statistics and voxel-based morphometry. Clin Neuroradiol. https://doi.org/10.1007/s00062-019-00865-2

21. Vemuri P, Knopman DS, Jack CR Jr, Lundt ES, Weigand SD, Zuk SM, Thostenson KB, Reid RI, Kantarci K, Slinin Y, Lakshminarayan K, Davey CS, Murray A (2017) Association of kidney function biomarkers with brain mri findings: the BRINK Study. J Alzheimers Dis 55:1069-1082. https://doi.org/10.3233/ JAD-160834

22. Zhang LJ, Wen J, Ni L, Zhong J, Liang X, Zheng G, Lu GM (2013) Predominant gray matter volume loss in patients with end-stage renal disease: a voxel-based morphometry study. Metab Brain Dis 28:647-654. https://doi.org/10.1007/s11011-013-9438-7

23. Alexander AL, Hurley SA, Samsonov AA, Adluru N, Hosseinbor AP, Mossahebi P, Tromp do PM, Zakszewski E, Field AS, (2011) Characterization of cerebral white matter properties using 
quantitative magnetic resonance imaging stains. Brain Connect 1:423-446. https://doi.org/10.1089/brain.2011.0071

24. Chou MC, Ko CH, Hsieh TJ, Chang JM, Chung WS (2019) A preliminary report of longitudinal white matter alterations in patients with end-stage renal disease: a three-year diffusion tensor imaging study. PLoS One 14:e0215942. https://doi.org/10.1371/journal. pone.0215942

25. Mu J, Chen T, Li P, Ding D, Ma X, Zhang M, Liu J (2018) Altered white matter microstructure mediates the relationship between hemoglobin levels and cognitive control deficits in end-stage renal disease patients. Hum Brain Mapp 39:4766-4775. https://doi.org/ $10.1002 / \mathrm{hbm} .24321$

26. Yin Y, Li M, Li C, Ma X, Yan J, Wang T, Fu S, Hua K, Wu Y, Zhan W, Jiang G (2018) reduced white matter integrity with cognitive impairments in end stage renal disease. Front Psychiatry 9:143. https://doi.org/10.3389/fpsyt.2018.00143

27. Findlay MD, Dawson J, Dickie DA, Forbes KP, McGlynn D, Quinn T, Mark PB (2019) Investigating the relationship between cerebral blood flow and cognitive function in hemodialysis patients. J Am Soc Nephrol 30:147-158. https://doi.org/10.1681/ ASN.2018050462

28. Tsuruya K, Yoshida H, Kuroki Y, Nagata M, Mizumasa T, Mitsuiki K, Yoshiura T, Hirakawa M, Kanai H, Hori K, Hirakata H, Kitazono T (2015) Brain atrophy in peritoneal dialysis and CKD stages 3-5: a cross-sectional and longitudinal study. Am J Kidney Dis 65:312-321. https://doi.org/10.1053/j.ajkd.2014.07.011

29. Gupta A, Lepping RJ, Yu AS, Perea RD, Honea RA, Johnson DK, Brooks WM, Burns JM (2016) Cognitive function and white matter changes associated with renal transplantation. Am J Nephrol 43:50-57. https://doi.org/10.1159/000444334

30. van Sandwijk MS, Ten Berge IJM, Caan MWA, During M, van Gool WA, Majoie C, Mutsaerts HMM, Schmand BA, Schrantee A, de Sonneville LMJ, Bemelman FJ (2020) Cognitive improvement after kidney transplantation is associated with structural and functional changes on MRI. Transplant Direct 6:e531. https://doi. org/10.1097/TXD.0000000000000976

31. Zhang R, Liu K, Yang L, Zhou T, Qian S, Li B, Peng Z, Li M, Sang S, Jiang Q, Sun G (2015) Reduced white matter integrity and cognitive deficits in maintenance hemodialysis ESRD patients: a diffusion-tensor study. Eur Radiol 25:661-668. https://doi.org/10. 1007/s00330-014-3466-5

32. Coupe P, Catheline G, Lanuza E, Manjon JV (2017) Towards a unified analysis of brain maturation and aging across the entire lifespan: a MRI analysis. Hum Brain Mapp 38:5501-5518. https:// doi.org/10.1002/hbm.23743

33. Matsuda-Abedini M, Fitzpatrick K, Harrell WR, Gipson DS, Hooper SR, Belger A, Poskitt K, Miller SP, Bjornson BH (2018) Brain abnormalities in children and adolescents with chronic kidney disease. Pediatr Res 84:387-392. https://doi.org/10.1038/ s41390-018-0037-5

34. Hartung EA, Erus G, Jawad AF, Laney N, Doshi JJ, Hooper SR, Radcliffe J, Davatzikos C, Furth SL (2018) Brain magnetic resonance imaging findings in children and young adults with CKD. Am J Kidney Dis 72:349-359. https://doi.org/10.1053/j.ajkd. 2017.11.024

35. Solomon MA, van der Plas E, Langbehn KE, Novak M, Schultz JL, Koscik TR, Conrad AL, Brophy PD, Furth SL, Nopoulos PC, Harshman LA (2021) Early pediatric chronic kidney disease is associated with brain volumetric gray matter abnormalities. Pediatr Res 89:526-532. https://doi.org/10.1038/s41390-020-01203-w

36. Kidney Disease: Improving Global Outcomes (KDIGO) CKD Work Group (2013) KDIGO 2012 Clinical Practice Guideline for the Evaluation and Management of Chronic Kidney Disease. Kidney Int Suppl 3.https://doi.org/10.1038/kisup.2012.76
37. Haverman L, van Rossum MA, van Veenendaal M, van den Berg JM, Dolman KM, Swart J, Kuijpers TW, Grootenhuis MA (2013) Effectiveness of a web-based application to monitor health-related quality of life. Pediatrics 131:e533-543. https://doi.org/10.1542/ peds.2012-0958

38. Onderwijsindeling S (2016) Standard Educational Classification. Den Haag/Heerlen: Centraal Bureau voor de Statistiek [Statistics Netherlands]

39. Schwartz GJ, Munoz A, Schneider MF, Mak RH, Kaskel F, Warady BA, Furth SL (2009) New equations to estimate GFR in children with CKD. J Am Soc Nephrol 20:629-637. https://doi. org/10.1681/ASN.2008030287

40. Levey AS, Coresh J, Greene T, Marsh J, Stevens LA, Kusek JW, Van Lente F (2007) Expressing the Modification of Diet in Renal Disease Study equation for estimating glomerular filtration rate with standardized serum creatinine values. Clin Chem 53:766772. https://doi.org/10.1373/clinchem.2006.077180

41. Okuda Y, Soohoo M, Tang Y, Obi Y, Laster M, Rhee CM, Streja E, Kalantar-Zadeh K (2019) Estimated GFR at Dialysis initiation and mortality in children and adolescents. Am J Kidney Dis 73:797-805. https://doi.org/10.1053/j.ajkd.2018.12.038

42. Hackman DA, Farah MJ (2009) 42Socioeconomic status and the developing brain. Trends Cogn Sci 13:65-73. https://doi.org/10. 1016/j.tics.2008.11.003

43. Nichols TE, Holmes AP (2002) Nonparametric permutation tests for functional neuroimaging: a primer with examples. Hum Brain Mapp 15:1-25. https://doi.org/10.1002/hbm.1058

44. Cohen J (1988) Statistical power analysis for the behavioral sciences. Routledge, New York

45. Oishi Y, Xu Q, Wang L, Zhang BJ, Takahashi K, Takata Y, Luo YJ, Cherasse Y, Schiffmann SN, de Kerchove DA, Urade Y, Qu WM, Huang ZL, Lazarus M (2017) Slow-wave sleep is controlled by a subset of nucleus accumbens core neurons in mice. Nat Commun 8:734. https://doi.org/10.1038/s41467-017-00781-4

46. Darwish AH, Abdel-Nabi H (2016) Sleep disorders in children with chronic kidney disease. Int J Pediatr Adolesc Med 3:112118. https://doi.org/10.1016/j.ijpam.2016.06.001

47. Eloot S, Schepers E, Barreto DV, Barreto FC, Liabeuf S, Van Biesen W, Verbeke F, Glorieux G, Choukroun G, Massy Z, Vanholder R (2011) Estimated glomerular filtration rate is a poor predictor of concentration for a broad range of uremic toxins. Clin J Am Soc Nephrol 6:1266-1273. https://doi.org/10.2215/CJN. 09981110

48. Bechstein WO (2000) Neurotoxicity of calcineurin inhibitors: impact and clinical management. Transpl Int 13:313-326. https:// doi.org/10.1111/j.1432-2277.2000.tb01004.x

49. Toyoda K (2015) Cerebral small vessel disease and chronic kidney disease. J Stroke 17:31. https://doi.org/10.5853/jos.2015.17.1.31

50. Haight T, Nick Bryan R, Erus G, Hsieh MK, Davatzikos C, Nasrallah I, D’Esposito M, Jacobs DR Jr, Lewis C, Schreiner P, Sidney S, Meirelles O, Launer LJ (2018) White matter microstructure, white matter lesions, and hypertension: an examination of early surrogate markers of vascular-related brain change in midlife. Neuroimage Clin 18:753-761. https://doi.org/10.1016/j. nicl.2018.02.032

Publisher's note Springer Nature remains neutral with regard to jurisdictional claims in published maps and institutional affiliations. 